\title{
Mapa de usos potenciales de la tierra de Galicia. Una perspectiva arqueológica
}

\author{
A map of the potential land use of Galicia. An archaeological perspective
}

\author{
Brais X. Currás Refojos (*)
}

\section{RESUMEN}

La cartografía de usos potenciales de la tierra es una herramienta de gran utilidad en el estudio de las formas de poblamiento y su relación con la explotación de los recursos agrícolas desde el enfoque de la arqueología del paisaje. La digitalización de esta información permite su aplicación sistemática en el análisis del territorio mediante SIG. En este trabajo se presenta el Mapa de usos potenciales de la tierra de Galicia, reclasificado en tres tipos establecidos en función de criterios históricos. Se muestra el procedimiento analítico desarrollado para la selección y clasificación de los tipos de tierra y su sistema de digitalización. Se examina la validez de esta fuente para la investigación arqueológica de las formas agrícolas en la antigüedad desde el punto de vista del análisis del territorio y se ofrece una visión crítica sobre sus ventajas y limitaciones.

\begin{abstract}
A digital version of the map of potential land use of Galicia is here presented, adapted to a reclassification of three types of potential land use, established using historical criteria. An analytical procedure is developed to select the land-types and the system used for their digitalisation. In the final part the map is used to critically revise the possibilities of using this record for territorial characterisation in archaeological research.
\end{abstract}

Palabras clave: Arqueología del Paisaje; Agricultura; Edad del Hierro; Imperio Romano; Sistemas de Información Geográfica-SIG; Galicia; Península Ibérica; Europa occidental.

(*) Grupo Estructura Social y Territorio-Arqueología del Paisaje (EST-AP), Departamento de Arqueología y Procesos Sociales, Instituto de Historia, Centro de Ciencias Humanas y Sociales (CCHS), Consejo Superior de Investigaciones Científicas (CSIC). C/ Albasanz 26-28. 28037 Madrid (España).

Correo e.: brais.curras@cchs.csic.es

Recibido 28-XI-2012; aceptado 15-II-2013.
Key words: Land evaluation; Landscape Archaeology; Agriculture; Iron Age; Roman Empire; Geographical Information Systems-GIS; Galicia; Iberian Peninsula; Western Europe.

\section{INTRODUCCIÓN}

La relación entre los recursos y las formas de ocupación del territorio es fundamental en el análisis arqueológico del paisaje al aproximarnos al conocimiento de la lógica locacional seguida en las estrategias de poblamiento. Buena parte de los estudios llevados a cabo en el Noroeste de la Península Ibérica han analizado la relación del poblamiento con los recursos desde un punto de vista descriptivo y no sistemático. Comúnmente describen de modo general los recursos de la región, el clima, las condiciones litológicas y los usos de la tierra sin evaluar la interacción de las estrategias de poblamiento con las posibilidades de acceso a los recursos. El espacio productivo aparece como un marco de referencia, una estampa de fondo sin relación con la naturaleza del asentamiento humano y su significación histórica. Cuando la hay es determinista: el poblado ve condicionadas sus posibilidades de existencia por las constricciones que impone el medio (Orejas 1995).

En contraposición, una serie de autores ha puesto el acento sobre la relación de cada asentamiento con los recursos potenciales, asumiendo la interdependencia entre la elección del emplazamiento y las posibilidades de explotación del paisaje. El espacio deja de ser el marco que delimita las condiciones de reproducción de los grupos humanos y se convierte en otro de interacción donde las sociedades construyen el paisaje a través de su relación con el medio. De este modo, 
el estudio ya no se plantea de modo general para toda una región, sino vinculado a las formas de ocupación de un territorio concreto. Las metodologías son distintas: uso de mapas de clases agrológicas (Agrafoxo 1989; Pombo 1993; Esparza y Larrazabal 2001), mapas de usos actuales de la tierra (Pombo 1993), mapas edafológicos (Camino 1995) (1), mapas de potencialidad agrícola (Xusto 1993; Carballo 2001; Parcero 2002; Fábrega 2005) y estudios específicos que evalúan el potencial agrícola bien mediante fotointerpretación (Fernández-Posse y Sánchez-Palencia 1988), bien a través de un análisis multi-variable de las condiciones edáficas, climáticas y topográficas (Álvarez 1993; Orejas 1996).

En este trabajo presento el mapa de usos potenciales de la tierra para todo el territorio gallego, obtenido a partir de una reclasificación controlada con un criterio arqueológico del Mapa de Capacidad Productiva de los Suelos de Galicia (MCPSG) elaborado por F. Díaz-Fierros y F. Gil (1984). La cartografía resultante ofrece una nueva herramienta de análisis con un gran potencial para el desarrollo de estudios arqueológicos que desde una perspectiva territorial afrontan el análisis de las formas de producción agrícola. Esta herramienta es parte de los resultados de mi investigación doctoral sobre las Transformaciones sociales y territoriales en la cuenca del Baixo Miño entre la Edad del Hierro y la integración en el Imperio Romano. Se inserta en la trayectoria del grupo de investigación Estructura Social y Territorio-Arqueología del Paisaje (EST-AP), dedicado de manera primordial al estudio de los espacios y los usos agrícolas en la antigüedad durante los últimos 30 años.

Esta aportación tiene un carácter fundamentalmente metodológico. Me centraré en dos cuestiones. Describo el proceso de elaboración del mapa de usos potenciales de la tierra de Galicia, mostrando los criterios seguidos en la selección y reclasificación de los tipos de tierra, así como el procedimiento técnico empleado para su digitalización. De forma simultánea, abordo el examen de las ventajas y limitaciones que ofrece este tipo de fuente de información para el análisis históri-

(1) Otro ejemplo en Almeida, C. A. Brochado de 1996: Povoamento romano do litoral minhoto entre o Cávado e o Minho. Tesis doctoral inédita, deposita en la Universidade do Porto. Portugal, 7 vols. co, en contraposición a otros documentos y enfoques diferentes.

\section{LA REPRESENTACIÓN \\ CARTOGRÁFICA DE LOS USOS DEL SUELO Y SU APLICACIÓN AL ANÁLISIS DE TERRITORIO}

La cartografía temática para la evaluación del potencial agrícola de una región es un recurso fundamental, que ha sido aplicado con asiduidad al analizar las formas de poblamiento antiguo. Agrupamos esta cartografía en tres clases: mapas de usos del suelo, de clases agrológicas y de capacidades de la tierra y proponemos como alternativa el desarrollo de cartografía específica.

Existe una abundante producción cartográfica que evalúa el uso de la tierra desde la perspectiva concreta del momento presente. Las hojas 1:50.000 del Mapa de Cultivos y Aprovechamientos publicadas en España durante los 1980 reflejaban los usos agrario y forestal. En fechas más recientes los proyectos CORINE Land Cover o el Sistema de Información sobre Ocupación del Suelo de España (2) recogen los distintos usos de la tierra en un sentido amplio.

Estos mapas ofrecen una imagen estática de esos usos en un momento singular. Es una información geográfica destinada fundamentalmente a la ordenación del territorio, que atiende a las condiciones específicas actuales del uso del suelo. Su utilidad desde un punto de vista histórico es muy reducida ya que ni refleja el uso potencial de la tierra, ni describe las características estructurales de la misma que pudieran servir de apoyo para evaluarlo. Además, la dimensión de los usos actuales de la tierra está obviamente afectada por importantes transformaciones que no permiten establecer comparaciones diacrónicas.

Los mapas de usos del suelo basados en la división en "clases agrológicas" se hicieron comunes desde los años 1950. Este sistema jerarquiza los tipos de suelo según su respectiva capacidad. Cada uno de los ocho tipos establecidos en los Mapas de Clases Agrológicas, editados en España a partir de los 1970, siguen estos principios metodológicos. De un uso definido por "la

(2) Ambos disponibles en el Centro Nacional de Información Cartográfica: http://centrodedescargas.cnig.es/CentroDescargas/ inicio.do (consulta 11-XII-2013).

Trab. prehist., 71, N. ${ }^{\circ}$ 1, enero-junio 2014, pp. 23-41, ISSN: 0082-5638

doi: $10.3989 /$ tp. 2014.12122 
intensidad máxima de explotación a que puede someterse un terreno" se pasa al situado "en el límite económico de la mejora en cuanto a su dedicación a sostener una vegetación herbácea permanente por lo que suelen considerarse como suelos forestales" (Anón. 1977: 17 y 23). F. DíazFierros y F. Gil (1984: 10) apuntan dos inconvenientes fundamentales en este tipo de trabajos. La tierra no se clasifica por su potencial, sino en función de sus limitaciones para la producción de una forma de cultivo ideal bajo condiciones actuales. Ello de partida resta representatividad a la evaluación de cualquier cultivo cuya producción requiera exigencias o sistemas de explotación distintos. Además, como los Mapas de Clases Agrológicas no permiten ponderar la calidad de la tierra en función de su potencial, no sirven ni para fijar las condiciones óptimas para su uso en diferentes escenarios técnicos, ni para proyectar diacrónicamente formas de uso alternativas. Considerando ambas objeciones cabe concluir que esta cartografía reviste notables inconvenientes en su aplicación al análisis histórico de las formas de explotación de la tierra al dificultar la valoración de las estrategias productivas desarrolladas desde un punto de vista diferente al de la lógica moderna.

En los 1970 aparecen los mapas de capacidades de la tierra. Su enfoque se basa en evaluar las cualidades y potencialidad de las tierras, en vez de sus limitaciones. Este estudio analiza la aptitud del suelo para cualquier tipo de cultivo en cualesquiera condiciones a partir de distintas variables en lugar de tomar una forma concreta de cultivo como referente y establecer los factores que limitan su desarrollo óptimo. Sigue las directrices de la land suitability evaluation de la Food and Agriculture Organization (FAO) (Anón. 1976), un análisis multi-variable que evalúa la geología, la edafología, el clima, las condiciones topográficas y geomorfológicas y la hidrología. Este enfoque no investiga los efectos económicos de los obstáculos para el desarrollo de un cultivo de referencia, sino las características estructurales de la tierra y sus cualidades en un sentido potencial. Desde esa base, y mediante criterios de conversión determinados por las condiciones socioeconómicas de la producción, se establecen correlaciones que identifican la capacidad de la tierra para cualquier tipo de cultivo, desde los cultivos forestales menos exigentes, hasta la producción hortícola más intensiva. Como novedad, el concepto de suelo se sustituye por el de tierra, mucho más rico e integrador de los factores ambientales que condicionan la producción (clima, hidrología, relieve, etc.), acción humana incluida (Anón. 1976: 11).

Los mapas de usos del suelo se basaban en clases agrológicas que reflejaban la actividad en un momento concreto y un uso de la tierra condicionado por los medios técnicos. Por el contrario, en el enfoque de las capacidades de la tierra, esos medios pueden ser analizados desde una consideración histórica. Los mapas de usos y los de clases agrológicas suelen reflejar una optimización de la explotación desde una perspectiva contemporánea. En cambio el nuevo enfoque, que está también orientado a la puesta en práctica de un uso óptimo de la tierra, igualmente permite plantear una valoración de formas sociales distintas de explotación agrícola. La ventaja de emplearlo para el análisis histórico de las formas de producción agrícola es que, al posibilitar un acercamiento más contextual a la comprensión del uso de la tierra, permite valorar formas de agricultura que no se rigen por criterios modernos (Van Joolen 2002). La cartografía generada desde la metodología formulada por la $F A O$ no cierra el uso de la tierra, ni su aptitud para un cultivo determinado en función de unas condiciones técnicas concretas, sino que ofrece una herramienta para la evaluación de la potencialidad de la tierra en diferentes condiciones socioeconómicas. $\mathrm{Su}$ ventaja es que permite llevar a cabo estudios diacrónicos de las formas de explotación agrícola. La clasificación de la tierra no es un punto de partida condicionado por los usos y necesidades actuales sino que se establece según criterios históricos. Se elimina así el enfoque presentista que pondera la potencialidad de la tierra en función de su uso óptimo considerado desde la lógica capitalista vigente. Por ello esta base metodológica ha servido de apoyo a distintos análisis arqueológicos del territorio, llevados a cabo en contextos históricos y geográficos dispares (Finke et al. 1994; Kamermans 2000; Van Joolen, 2002, 2003; Verhagen 2002; Mayoral 2004; Attema y Haas 2005; Attema et al. 2011).

Una alternativa a la falta de cartografía temática publicada, basada en análisis formalizados de las capacidades de la tierra, es desarrollar otra específica, fundamentada en los mismos parámetros y circunscrita al área de estudio. Ejemplo de ello es el análisis de A. Orejas (1996: 47, lám. 3) 
para la cuenca noroccidental del Duero que puso en consideración la pendiente, la edafología, la litología, el clima y la red de drenaje. Fábrega et al. (2005) plantean un desarrollo más avanzado, manejando un análisis computerizado mediante uso de SIG, para los castros de O Neixón que toma como referencia los parámetros de pendiente, red de drenaje e insolación. Esta metodología abre las puertas a analizar la accesibilidad a recursos agrícolas mediante una cartografía de mayor detalle y precisión que la que aportan los mapas existentes basados en el enfoque de la evaluación de las capacidades de la tierra. Sin embargo, su implementación hará necesario incorporar variables irrenunciables como la litología, las condiciones climáticas o el nivel de pedregosidad. Las dos primeras son asumibles sin grandes problemas para Galicia donde hay trabajos sobre la variación climática actual (Martínez Cortizas y Pérez Alberti 1999) y durante el Holoceno (Martínez Cortizas et al. 2009), así como una cartografía específica sobre las características litológicas del suelo (3). En cambio analizar el grado de pedregosidad, la presencia de litosoles, el tipo de suelos o su profundidad, factores determinantes en la evaluación de la tierra, requiere la aplicación de sistemas de teledetección más complejos (Uriarte et al. 2008).

\section{EL MAPA DE CAPACIDAD PRODUCTIVA DE LOS SUELOS DE GALICIA}

F. Díaz-Fierros y F. Gil (1984), a partir de la base metodológica desarrollada por la $F A O$, publicaron el Mapa de Capacidad Productiva de los Suelos de Galicia (MCPSG). Estaba pensado como una contribución al desarrollo agrario de Galicia pero a la vez aportaba una cartografía de ese territorio, susceptible de un análisis diacrónico a partir de criterios históricos y arqueológicos. Desde un momento muy temprano fue utilizado en el proyecto de investigación del área de $\mathrm{O}$ Bocelo (1987-1989) (Criado 1992) y en el análisis territorial del castro de Torroso (1984-1990) (Peña Santos 1992). M. Xusto (1993) lo tomó

(3) Mapa geológico y litológico de Galicia disponible en formato digital vectorizado entre los productos cartográficos del Sistema de Información Territorial de Galicia: http://sitga.xunta. es/cartografia (consulta 11-XII-2013). como referencia general en el estudio de A Terra de Viana do Bolo. C. Parcero (2002; Parcero y Fábrega 2006) estableció una nueva clasificación del MCPSG controlada, por vez primera, por criterios históricos y aplicando SIG. La senda que abrió ha sido continuada en varios trabajos (Fábrega 2005; Pungín 2009; Vázquez Mato 2010). X. Carballo (2001), en su investigación de A Terra de Deza, en lugar del MCPSG, tomó como base un estudio comarcal más preciso, pero articulado según principios equivalentes.

El MCPSG clasifica la tierra según las cualidades que determinan su potencial productivo. El resultado es una división del territorio en unidades fisiográficas de cualidades homogéneas, identificadas con un código (e.g. $\mathrm{B} \mathrm{M}_{74 \mathrm{~S}}$ ) en donde la primera letra identifica las cualidades estructurales de las tierras, la segunda letra el sometimiento al riesgo de heladas, el primer número el régimen hídrico, el segundo la disponibilidad de nutrientes y la última letra la toxicidad del suelo. La primera variable divide las cualidades estructurales de las tierras en 7 categorías (A-G) en función de la pendiente, la profundidad del suelo, la cantidad de afloramientos rocosos y el riesgo de erosión (Tab. 1). Este parámetro trata de evaluar las posibilidades de implantar una agricultura mecanizada. Su gran valor para estudiar el uso de la tierra en la antigüedad es que las principales

\begin{tabular}{|c|c|c|c|c|}
\hline Clase & $\begin{array}{c}\text { Pendiente } \\
\text { \% }\end{array}$ & $\begin{array}{c}\text { Aflora- } \\
\text { mientos } \\
\text { \% }\end{array}$ & $\begin{array}{c}\text { Profun- } \\
\text { didad } \\
\text { cm }\end{array}$ & $\begin{array}{c}\text { Riesgo } \\
\text { erosión }\end{array}$ \\
\hline $\mathbf{A}$ & $<3$ & $<10$ & $>100$ & $1-2$ \\
\hline $\mathbf{B}$ & $<3$ & $<10$ & $50-100$ & $1-2$ \\
& $3-10$ & $<10$ & $>100$ & $2-3$ \\
\hline & $<3$ & $10-25$ & $50-100$ & $1-2$ \\
$\mathbf{C}$ & $<10$ & $10-25$ & $>100$ & $2-3$ \\
& $3-10$ & $<10$ & $50-100$ & $1-3$ \\
\hline \multirow{2}{*}{$\mathbf{D}$} & $3-10$ & $<25$ & $>50$ & 4 \\
& $3-10$ & $10-25$ & $50-100$ & $1-3$ \\
& $10-20$ & $<25$ & $>50$ & $2-3$ \\
\hline \multirow{2}{*}{$\mathbf{E}$} & $10-20$ & $<25$ & $>50$ & 4 \\
& $20-35$ & $<25$ & $>50$ & $3-4$ \\
\hline $\mathbf{F}$ & $<35$ & $<25$ & $25-50$ & $1-4$ \\
\hline $\mathbf{G}$ & $>35$ & $25-50$ & $>25$ & $1-4$ \\
& $35-50$ & $<50$ & $>25$ & 4 \\
\hline
\end{tabular}

Tab. 1. Cualidades estructurales de la tierra en el Mapa de Capacidad Productiva de los Suelos de Galicia. 
características de la misma son "muy difícilmente modificable[s]" (Díaz-Fierros y Gil Sotre 1984: 15). El campo gallego ha sido objeto de una profunda transformación a lo largo de los siglos. Las tierras con demasiada pendiente o con suelos poco profundos fueron adecuadas con la construcción de bancales y aterrazamientos y por medio de desmontes. Estas tierras son clasificadas como $\overline{\mathrm{C}}$ (tipo $\mathrm{D}$ original mejorado) y $\overline{\mathrm{D}}$ (tipo $\mathrm{E}$ mejorado).

Según el régimen térmico se establecen 5 categorías en función de la duración de la temporada de riesgo de heladas. Se expresa a partir de un tipo de cultivo ideal, cuya producción se hace inviable desde ese nivel: Limonero $<3$ meses; Maíz entre 3-6 meses; Patata 6-7,5 meses; Trigo 7,5-9 meses; Nardus $>9$ meses.

La variable del régimen hídrico de los suelos se evalúa a partir de 9 categorías. Las tierras con exceso de agua están entre 1 y 4 y las que presentan un déficit de precipitación entre 5 y 9 (Tab. 2). La valoración de las tierras de acuerdo con el régimen pluvial cuenta con 5 categorías que clasifican los suelos bien drenados según el número de días anuales con déficit de precipitación.
La disponibilidad de nutrientes de la tierra considera otras 5 categorías según la presencia de los principales macronutrientes (Tab. 2). El criterio de clasificación del MCPSG no se basa en el muestreo y análisis de los suelos, ya que la práctica, habitual en el campo gallego, de incorporar nutrientes artificiales podría restar representatividad a los resultados. Considera la fertilidad potencial dependiente del tipo de suelo, una característica estructural de la tierra que se puede proyectar sin problemas hacia el pasado.

Solo se señala la toxicidad debida a salinidad (suelos s) o níquel (suelos $\mathrm{n}$ ).

\section{EL USO POTENCIAL DE LA TIERRA EN GALICIA ENTRE \\ LA PROTOHISTORIA Y LA INTEGRACIÓN EN EL IMPERIO ROMANO}

El MCPSG aporta de partida una evaluación objetiva de las cualidades de la tierra. Pero esta fuente por si misma no responde a la pregunta de cuáles fueron las formas de explotación del territorio durante la antigüedad. Su utilidad para la

\begin{tabular}{|c|c|}
\hline Clase & \multicolumn{1}{|c|}{ Régimen hídrico } \\
\hline \multicolumn{2}{|c|}{ Exceso de Agua } \\
\hline $\mathbf{1}$ & $\begin{array}{l}\text { Suelos tipo marsh, sumergidos permanen- } \\
\text { te o casi permanentemente }\end{array}$ \\
\hline $\mathbf{2}$ & $\begin{array}{l}\text { Suelos tipo gley, suelos arcillosos sumer- } \\
\text { gidos casi permanentemente, con la capa } \\
\text { freática alta. }\end{array}$ \\
\hline $\mathbf{3}$ & $\begin{array}{l}\text { Suelos pseudogley, anmoor o pelosoles, } \\
\text { con la capa freática alta, pero que desapa- } \\
\text { rece en verano. }\end{array}$ \\
\hline $\mathbf{4}$ & \multicolumn{1}{c|}{ Suelos bien drenados } \\
\hline & Días con déficit de precipitación \\
\hline $\mathbf{5}$ & $<30$ días \\
\hline $\mathbf{6}$ & 60 - 60 días \\
\hline $\mathbf{7}$ & 90 días \\
\hline $\mathbf{8}$ & $>120$ días \\
\hline $\mathbf{9}$ & días \\
\hline
\end{tabular}

\begin{tabular}{|c|l|}
\hline Clase & \multicolumn{1}{|c|}{ Disponibilidad potencial de nutrientes } \\
\hline $\mathbf{1}$ & $\begin{array}{l}\text { Suelos con disponibilidad óptima } \\
\mathrm{pH}>6,5 \\
\text { saturación }>75 \%\end{array}$ \\
\hline $\mathbf{2}$ & $\begin{array}{l}\text { Suelos con disponibilidad buena } \\
\mathrm{pH}>5,5 \\
\text { saturación }>50 \%\end{array}$ \\
$\mathbf{3}$ & $\begin{array}{l}\text { Suelos derivados de rocas calizas y es- } \\
\text { quistos del complejo de Ordenes con dis- } \\
\text { ponibilidad moderada } \\
\text { pH }>5 \\
\text { saturación } 15-50 \%\end{array}$ \\
$\mathbf{4}$ & $\begin{array}{l}\text { Suelos derivados de rocas graníticas y es- } \\
\text { quistos con disponibilidad mala. } \\
\text { pH 4,5 - 5 } \\
\text { saturación 7 - 15\% }\end{array}$ \\
\hline $\mathbf{5}$ & $\begin{array}{l}\text { Suelos derivados de areniscas, cuarcitas y } \\
\text { materiales sedimentarios con disponibili- } \\
\text { dad muy deficiente. } \\
\text { pH }<4,5 \\
\text { saturación }<7 \%\end{array}$ \\
\hline
\end{tabular}

Tab. 2. Clasificación del régimen hídrico y de la disponibilidad de nutrientes en el Mapa de Capacidad Productiva de los Suelos de Galicia. 
valoración de las formas productivas de una sociedad concreta pasa necesariamente por la consideración singular de factores socioeconómicos y tecnológicos determinados. En palabras de Díaz-Fierros y Gil Sotre (1984: 44), "la traducción de las clases de tierras en términos de productividad solo tiene un sentido real cuando se definen los usos específicos de la tierra y con relación a ellos se establecen los distintos grados de aptitud de las mismas".

Para manejar los datos del MCPSG en relación con las formas de ocupación y organización del paisaje en época antigua es necesario establecer una reducción de las unidades de tierra a un número limitado de clases que tengan un contenido históricamente significativo. El proceso de modelización que traduce sus valores a los parámetros de la agricultura antigua tiene dos pasos. Primero se definen las condiciones de la práctica agrícola en época antigua y los usos posibles de la tierra. Después se establecen los criterios de conversión del MCPSG para la selección de tipos de tierra acordes con esos usos.

Caracterizar la práctica agrícola para la Edad de Hierro y época Romana en el Noroeste de la Península Ibérica es una labor compleja que numerosos trabajos han abordado en detalle (Parcero 2002; Teira 2010a). No me extenderé sobre la cuestión pues me interesa únicamente presentar las formas posibles de producción agrícola. Tomo como modelo la división bipartita establecida por C. Parcero (2002), los trabajos existentes y la consideración del registro arqueológico y carpológico para proponer dos tipos ideales generales de práctica agrícola: intensivo y extensivo.

La agricultura de carácter intensivo es de rendimientos constantes con ciclos de rotación complejos que pueden aportar dos cosechas anuales. Se emplea un tipo de suelo rico en nutrientes y con un elevado nivel hídrico, por lo que es difícil de roturar. En varios yacimientos de la Edad del Hierro se ha documentado trigo, cebada, mijo y distintas especies de leguminosas (Parcero 2002). La combinación de cereales de invierno y de primavera permite producir dos cosechas anuales con rotaciones complejas gracias a las leguminosas. Evidencias adicionales de esta agricultura intensiva son el utillaje documentado, incluyendo instrumental de hierro y los indicios de uso del arado (Parcero 2002).

La agricultura de carácter extensivo, basada en ciclos largos, es factible en suelos ligeros más fáciles de trabajar y opta por tierras bien drenadas y poco profundas. El uso del fuego en la roturación del monte, probablemente en relación con prácticas de agricultura extensiva, se ha documentado desde el Neolítico (Kaal et al. 2011).

Caben clasificaciones más complejas, atendiendo por ejemplo a todas las combinaciones posibles de cultivo y formas de rotación según las especies identificadas en el registro. Sin embargo la inclusión de un elevado número de variables podría oscurecer el análisis y distorsionar la visión de conjunto. Además de las condiciones socioeconómicas y técnicas que definen las formas productivas, se nos escapa un tercer factor que debería ser tenido en cuenta: la percepción de las cualidades de la tierra por las poblaciones antiguas y su capacidad de distinguir sus usos potenciales (Verhagen 2002). Para época romana contamos con el testimonio de los agrónomos para otras zonas del Imperio, pero no podemos saber si los grupos indígenas prerromanos y romanos del Noroeste de la Península Ibérica distinguían uno, dos o más tipos de tierra.

A partir de los tipos ideales de agricultura mencionados he establecido una división equivalente de tipos de tierra, ampliada con un tercero de uso nulo, correspondiente a zonas donde $a$ priori cualquier práctica agrícola es imposible. Las tierras de uso intensivo ocupan el fondo de los valles. Son suelos pesados, ricos en nutrientes, sin litosoles ni zonas pedregosas significativas. Permiten el desarrollo de una agricultura intensiva, con ciclos cortos y rotaciones complejas, susceptible de aportar varias cosechas al año. Las tierras de uso extensivo tienen suelos ligeros, bien drenados. Sus limitaciones para una agricultura de ciclos largos están relacionadas con el clima o las características litológicas del suelo. Las tierras no aptas para la agricultura adolecen de importantes deficiencias debidas a la pendiente, las propiedades del suelo y las condiciones climáticas. Como permiten captar recursos silvícolas y cinegéticos se han definido como tierras de captación (Orejas 1996) pero, por mi parte, he mantenido el calificativo de nulo al enfocar el análisis a los usos agrícolas.

Este esquema tripartito converge con el de algunos de los principales análisis del territorio del Noroeste que han clasificado la tierra en función de los usos posibles en época antigua. A. Orejas (1996) divide el uso potencial de los recursos entre "secano" (A y B), "regadío" y 
“captación”. El modelo de X. Carballo (2001) se basa en tres tipos de usos: de alta calidad, de baja calidad y no cultivable. El de C. Parcero (2002) los divide en aprovechamiento potencial intensivo, extensivo y nulo. La presente reclasificación del MCPSG se basa estrictamente en las condiciones de producción que se pueden deducir del registro arqueológico. No implica a priori una periodización o una jerarquización entre los usos potenciales, ni mucho menos la identificación de un uso determinado con una etapa histórica o una forma concreta de poblamiento.

El hecho de que desde el inicio de la Edad del Hierro pudiera desarrollarse una agricultura intensiva, basada en ciclos complejos y con dos cosechas anuales, nos invita a dejar de lado la explicación de los usos potenciales en un sentido evolutivo. Además, la disponibilidad de medios técnicos para una forma agrícola determinada no exige su puesta en práctica en esos mismos términos. El uso del MCPSG se ha centrado en dicho periodo pero se puede extender al mundo romano y la tardoantigüedad aunque sus formas respectivas de explotación agrícola son muy diferentes. Durante la Edad del Hierro se observa una progresiva intensificación agrícola en los procesos de reducción del polen arbóreo, cuya dinámica arranca en la Edad del Bronce (Aira et al. 1989; Martínez Cortizas et al. 2009). La llegada de Roma supone una ruptura inédita. La intensificación de la producción se refleja en la introducción de nuevos cultivos (Teira 2010b), el fuerte incremento en los procesos de deforestación (Kaal et al. 2011), el aumento proporcional de polen de cereal y el mayor peso de la ganadería (4). Los cambios no son solo tecnológicos si no que también afectan a la estructura socioeconómica al integrar en un sistema tributario a

(4) Gran parte de los estudios polínicos llevados a cabo en el Noroeste son on-site (Aira et al. 1989). Los recientes estudios off-site en turberas han aportado una visión mucho más precisa y ajustada para comprender la evolución del paisaje agrario. L. López Merino (2009. Paleoambiente y antropización en Asturias durante el Holoceno. Tesis doctoral inédita, Universidad Autónoma de Madrid) ha documentado los cambios relacionados con una intensificación de la producción a partir del cambio de era en Asturias. Es de especial relevancia el estudio de N. Silva Sánchez (2010. Cambios ambientales en los últimos 3000 años en el sector occidental de la sierra del Bocelo a partir de indicadores geoquímicos y palinológicos. Memoria de licenciatura inédita, Universidade de Santiago de Compostela) que revela la gran transformación ocurrida a partir de la conquista romana en $\mathrm{O}$ Bocelo donde, aparentemente, la presencia de Roma era menor (Criado 1992). comunidades regidas hasta la fecha por una economía fundamentalmente orientada hacia la autosuficiencia (Orejas y Sastre 1999).

La validez del mapa de usos potenciales de la tierra en el análisis del poblamiento a largo plazo reside en recoger un uso potencial, no uno objetivo. Es pertinente su utilización en relación con formas de economía campesina con un grado de desarrollo similar en lo esencial, en comparaciones orientadas a la comprensión de procesos históricos de cambio, comprendidos entre la Edad del Bronce Final y la Alta Edad Media.

He elaborado el "Mapa de usos potenciales de la tierra de Galicia" (MUPTGA) (Fig. 1) mediante unos criterios de conversión, basados en la valoración histórica propuesta, que reducen los parámetros de todas las unidades fisiográficas contenidas en la base cartográfica a solo tres de carácter potencial. Siguiendo los criterios de conversión del MCPSG, establezco la reclasificación en 3 usos potenciales en función de la mayor o menor aptitud de las cualidades de la tierra para el desarrollo de cada tipo de agricultura (Tab. 3). Mi referente principal en la valoración son las características estructurales de la tierra: pendiente, porcentaje de afloramientos, profundidad del suelo y riesgo de erosión. Criterios análogos en términos generales a los aplicados por C. Parcero (2002) para la misma fuente y por X. Carballo (2001).

Las tierras clasificadas como A B C $\bar{C}$ suelen presentar mejores condiciones para la agricultura intensiva, las tierras D $\bar{D}$ E para una agricultura extensiva y las $F \mathrm{G}$ son improductivas desde el punto de vista agrícola. Las tierras $\overline{\mathrm{C}}$ y $\overline{\mathrm{D}}$, originales $\mathrm{D}$ y $\mathrm{E}$, se han tomado en su modo mejorado. La documentación de formas de preparación del terreno agrícola tanto en la Protohistoria (Parcero 2002) como en época romana (Ruiz del Árbol 2005; Sánchez-Palencia et al. 2014), permite establecer que el espacio de cultivo sí era susceptible de ser transformado con el fin de mejorar la producción. A pesar de todo, en esta reclasificación las zonas aterrazadas con una pendiente superior al $40 \%$ no han sido consideradas como aptas para el cultivo.

Las condiciones térmicas no son especialmente desfavorables en Galicia para el desarrollo de la agricultura, salvo donde el riesgo de heladas puede representar un factor limitante. En las tierras de tipo L, M y $\mathrm{P}$ es posible el cultivo, frente al tipo N. El tipo M marca las tierras aptas para 


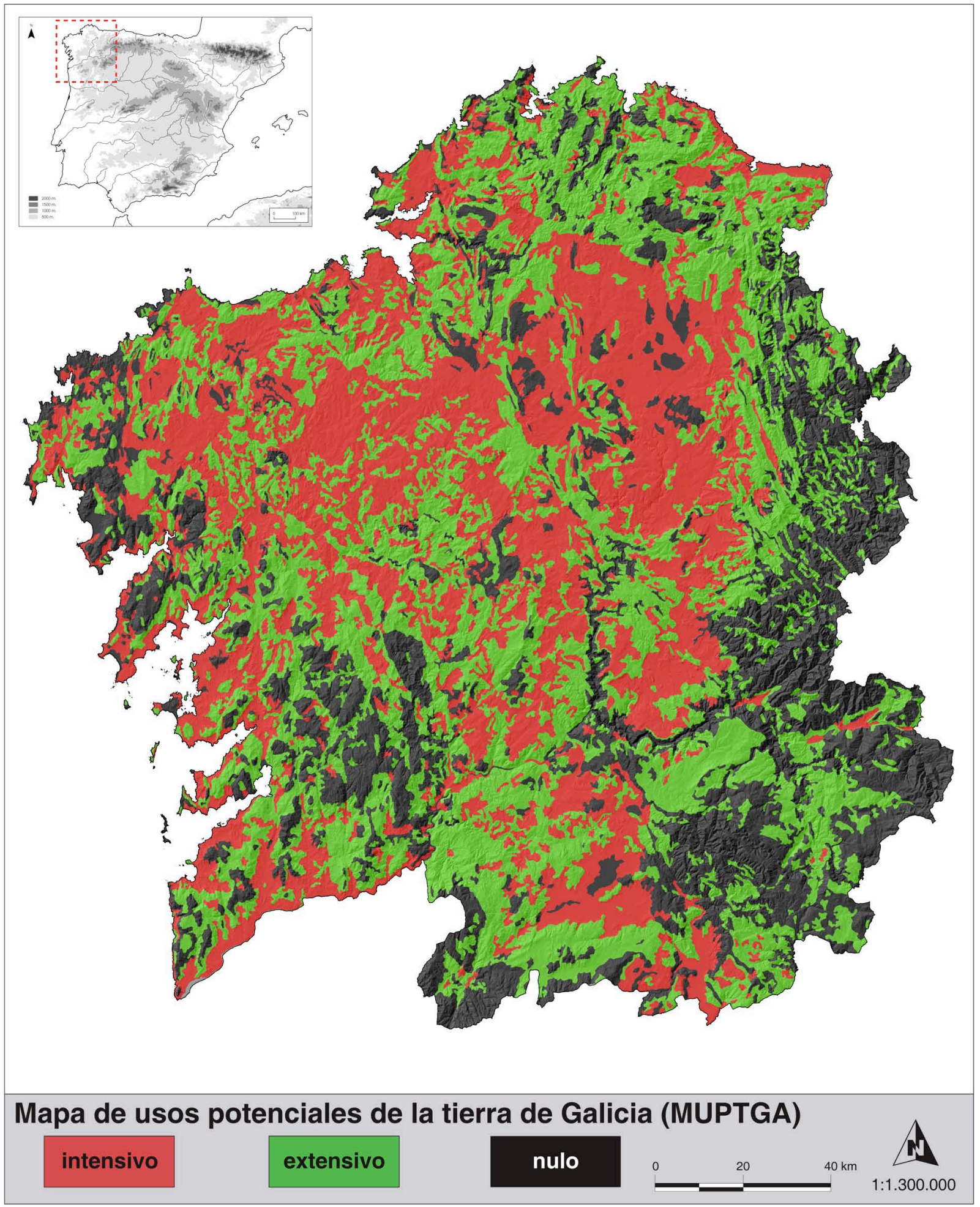

Fig. 1. Mapa de usos potenciales de la tierra de Galicia. 


\begin{tabular}{|l|c|c|c|}
\hline & Intensiva & Extensiva & Nula / captación recursos \\
\hline Pendiente & $<3-10 \%$ & $<10-35 \%$ & $>35 \%$ \\
\hline Pedregosidad & $<10-25 \%$ & $<25 \%$ & $>25-50 \%$ \\
\hline Profundidad & $>100 / 50-100 \mathrm{~cm}$ & $>50 \mathrm{~cm}$ & $<25 \mathrm{~cm}$ \\
\hline Riesgo de erosión & sin riesgo / riesgo moderado & riesgo moderado / grave & riesgo grave \\
\hline Riesgo de heladas & $<3-7,5$ meses & $<3-9$ meses & $7,5->9$ meses \\
\hline Régimen hídrico & $\geq 4$ & $\geq 4$ & $1-3$ \\
& $5-7$ & $5-8$ & $8-9$ \\
\hline
\end{tabular}

Tab. 3. Criterios de conversión del Mapa de Capacidad Productiva de los Suelos de Galicia a la reclasificación en tierras con tres usos potenciales de producción agrícola.

el maíz. Me parece una valoración muy restrictiva que puede ser válida como criterio de discriminación desde un punto de vista comparado en estudios comarcales concretos (Fábrega 2005) pero que plantea más problemas a escala regional. Casi toda la mitad occidental del territorio se ajusta a un régimen de heladas $\mathrm{P}$ o $\mathrm{T}$ por lo que, si se toma el tipo $\mathrm{M}$ como límite del uso intensivo, se genera una simplificación que elimina los matices en el uso potencial de la tierra. El tipo T constriñe la posibilidad de producir trigo. Son tierras donde la agricultura, al recurrir a especies más resistentes como la cebada o el mijo, reduce -aunque no excluye- la eventualidad de lograr dos cosechas anuales. Así, las tierras clasificadas como intensivas sometidas a un riesgo de heladas superior a los 7 meses al año (tipo T) han sido incluidas en bloque en el rango de tierras de potencial extensivo. Esta circunstancia concurre principalmente en las sierras sudorientales de Galicia, donde la amplitud térmica anual es mayor y la temperatura media menor (Martínez Cortizas y Pérez Alberti 1999).

El régimen hídrico no representa en términos globales una restricción considerable en el Noroeste. La mayoría de los suelos tiene unas condiciones adecuadas y un déficit de precipitación en general menor de 90 días anuales (tipos 5, 6 y 7): un margen poco significativo que no afecta al desarrollo de una agricultura de secano. Solo en el extremo sudoriental de Galicia y en la cuenca media del Miño el déficit de precipitación supera los 90 días anuales (tipos 8 y 9) (Martínez y Pérez 1999). Estos tipos suponen una devaluación en la clasificación de la tierra, de modo que un uso potencial intensivo tipo 8 se convierte en un uso extensivo, y un uso extensivo tipo 9 se convierte en un uso nulo. La mayoría de los sue- los están bien drenados $(\geq 4)$ menos en las zonas donde el exceso de agua durante todo o gran parte del año hace inviable cualquier forma de cultivo salvo que se lleven a cabo grandes trabajos de desecación. Por esta circunstancia, propia de las marismas o humedales interiores, pero también de suelos mal drenados, esas tierras se categorizan entre los tipos 1 y 3 . A efectos del análisis todas han sido reclasificadas como tierras de uso agrícola potencial nulo.

Es pertinente recordar aquí que para las variables climáticas me atengo a los parámetros, modernos, recogidos en el MCPSG. Un análisis más contextual exige en principio una aproximación paleoclimática (Verhagen 2002) que existe con carácter general (Font Tullot 1988) y específico para el Noroeste (Martínez Cortizas y Pérez Alberti 1999; Fábregas et al. 2003; Martínez Cortizas et al. 2009). Sería necesario determinar si las importantes oscilaciones en el régimen térmico y pluvial documentadas desde el 3.500 con el periodo neoglaciar, su final en torno al 1.500 a.C. o el periodo cálido romano iniciado con el cambio de era fueron un factor de alteración sustancial de las formas agrícolas.

La disponibilidad de nutrientes es una categoría muy poco significativa. La litología es un factor determinante en la calidad de los suelos, pero es muy poco relevante para el análisis de las tierras de Galicia. En su práctica totalidad son edáficamente pobres debido a su elevado grado de acidez ( $\mathrm{Ph}$ entre 4,5 y 5). Esta carencia histórica sólo fue compensada en fechas recientes con la introducción del uso sistemático de nutrientes. La excepción es el área noroccidental con una disponibilidad media de nutrientes concentrada en torno al complejo esquistoso de Ordes (tipo 3). Pero la marcada circunscripción territorial de es- 
tas condiciones desaconseja servirse de este parámetro en la evaluación de los usos potenciales de la tierra.

Los criterios de conversión que se han propuesto para el MCPSG pueden aplicarse directamente a cualquier otro mapa de capacidades de la tierra. Esta metodología estandarizada basada en los criterios de la FAO permite acometer tanto estudios comparativos a una escala amplia, como integrales mediante la convergencia de trabajos limítrofes. Por ejemplo, en mi investigación sobre la evolución de las formas de organización del territorio en la cuenca del Baixo Miño entre la Edad del Hierro y la integración en el Imperio romano combiné el MCPSG con la Carta dos solos e da aptidão da terra de entre-Douro e Minho (Anón. 1995). Ello permitió un estudio integrado del valle del Baixo Miño, trascendiendo la artificialidad de las fronteras modernas (Fig. 2).

\section{LA CARTOGRAFÍA DE LOS USOS DEL SUELO EN GALICIA: UN ANÁLISIS COMPARADO}

La importancia del MCPSG como base para estudiar la potencialidad productiva del territorio en arqueología del paisaje se pone de relieve al compararlo con otras fuentes cartográficas alternativas. Para contrastar las diferencias entre los mapas de clases agrológicas y de usos y la cartografía basada en las capacidades de la tierra, he tomado como ejemplo la hoja 48 (una zona del norte de Lugo) del Mapa Topográfico Nacional, escala 1:50.000 (Fig. 3).

El CORINE Land Cover (CLC) recoge para esta zona 8 usos: 1 urbano (89,7 ha), 2 de cultivo (cultivos 21.325 ha; cultivos con zonas de vegetación $11.900 \mathrm{ha}$ ) y 7 de forestal (bosques de frondosas 456,6; de coníferas $1.302,5$ ha; mixto $9.527,7$ ha; landas y matorrales 2.364 ha; matorral boscoso 3.273 ha). No hay ningún criterio válido para reclasificar estos tipos de suelo en clave histórica. Los usos actuales distorsionan la potencialidad real de la tierra y plasman exclusivamente la racionalidad económica y las condiciones tecnológicas de un momento concreto, así como las circunstancias contingentes que le afectan. Se podría argumentar que la identificación del uso actual de las especies más exigentes eventualmente permitiría determinar las tierras de uso potencial intensivo. Sin embargo lo que se iden- tifica en realidad es un uso actual, socialmente determinado, cuya delimitación es circunstancial y no se acomoda necesariamente al potencial real del territorio.

La arbitrariedad de los mapas de usos se aprecia con toda claridad al comparar el CLC con los usos del suelo en los 1950. He tomado como referencia la hoja I-48 del Mapa Topográfico Nacional, escala 1:25.000, trazando sobre ella la fotointerpretación de los usos del suelo a partir del mosaico ortorrectificado con la fotografía del "vuelo americano" (5) (ca. 1956) (Fig. 3). Se observan importantes cambios en la explotación de la tierra tanto en la cartografía como en la superficie dedicada a cada uso (Fig. 4). En los años $1950,11.155,8$ ha se dedicaban al cultivo $(89,4 \%)$, $1.158,3$ ha al pasto $(9,3 \%)$ y 156,7 ha al aprovechamiento forestal $(1,2 \%)$. Se puede decir que la práctica totalidad de la superficie se explotaba según el sistema agrario de la Galicia campesina. Incluso las zonas de uso forestal aparecen como pequeñas parcelas distribuidas entre los terrenos de cultivo, destinadas a la explotación silvícola. En la década de los 2000, la transformación de la explotación del territorio causada por los cambios en la estructura socioeconómica se hace evidente. La superficie de uso forestal, muy incrementada con los procesos de repoblación, se ha multiplicado por 15, 2.301,2 ha $(18,9 \%)$, mientras que las tierras de aprovechamiento agrícola se reducen a 9.880,3 ha, de las que el 35\% (3495,2 ha) tienen zonas con vegetación. Ello muestra el progresivo abandono del campo.

El Mapa de Clases Agrológicas (MCA) en su hoja 48 define 8 tipos de suelo en función de las limitaciones para el cultivo. Como la misma fuente establece de partida una división en 4 clases, la única reclasificación viable controlada por criterios históricos consiste en reducirla a 3 usos potenciales. Las clases I, II y III correspondientes al "laboreo sistemático" han sido identificadas con el uso potencial intensivo; la clase IV, de "laboreo ocasional", como de uso potencial extensivo y las clases V, VI y VII "no laborables" y la VIII "improductivo", como de uso potencial agrícola nulo. Las zonas cartografiadas como urbanas han sido reclasificadas por extrapolación.

(5) Servidor WMS del SITGA con la Ortofotografia Aérea do voo americano de 1956-1957 UTM29-ED50.

http://ideg.xunta.es/wms orto 1956-57/request.aspx (consulta 27-XII-2013). 


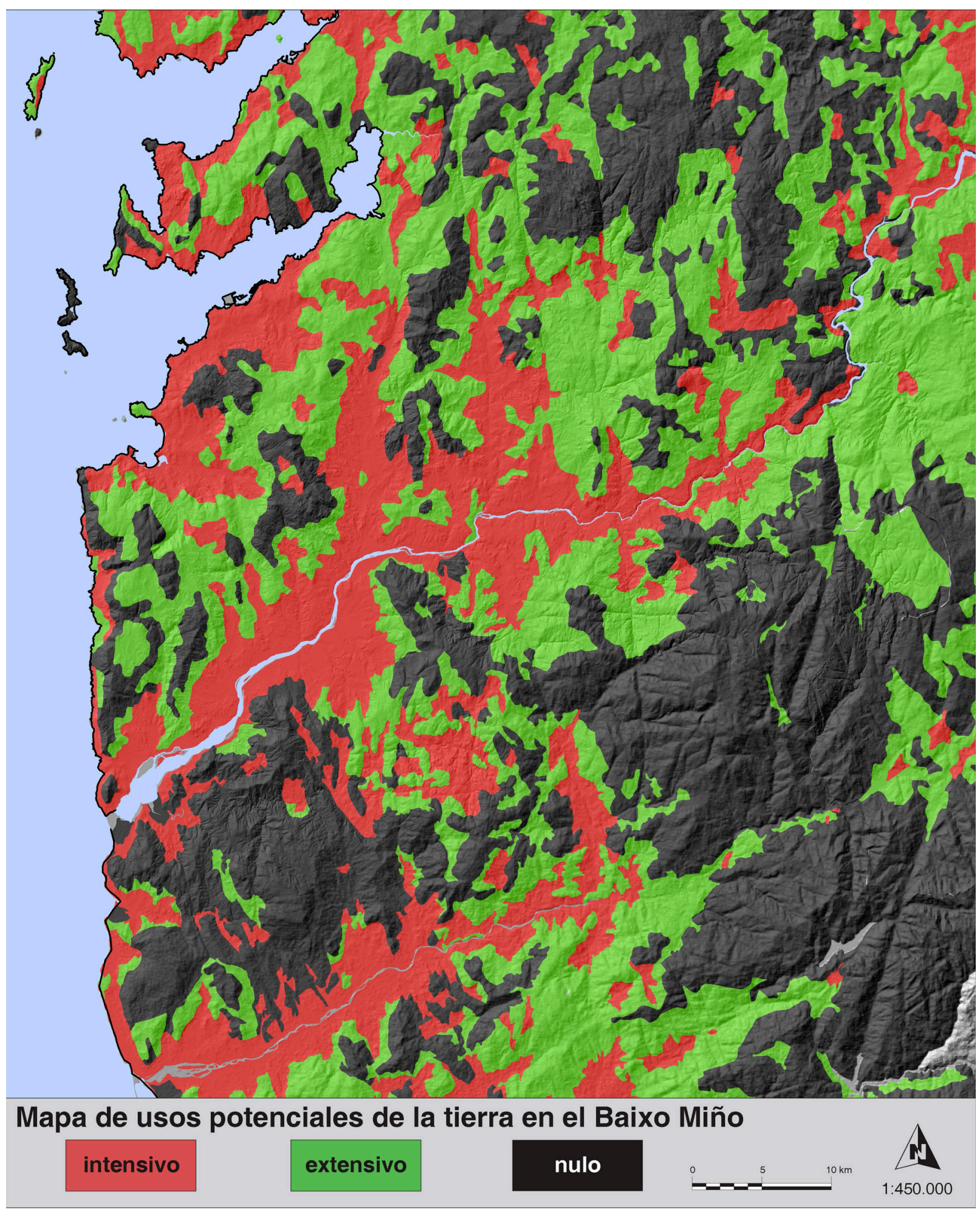

Fig. 2. Mapa de usos potenciales de la tierra en la Cuenca del Baixo Miño (Galicia). 

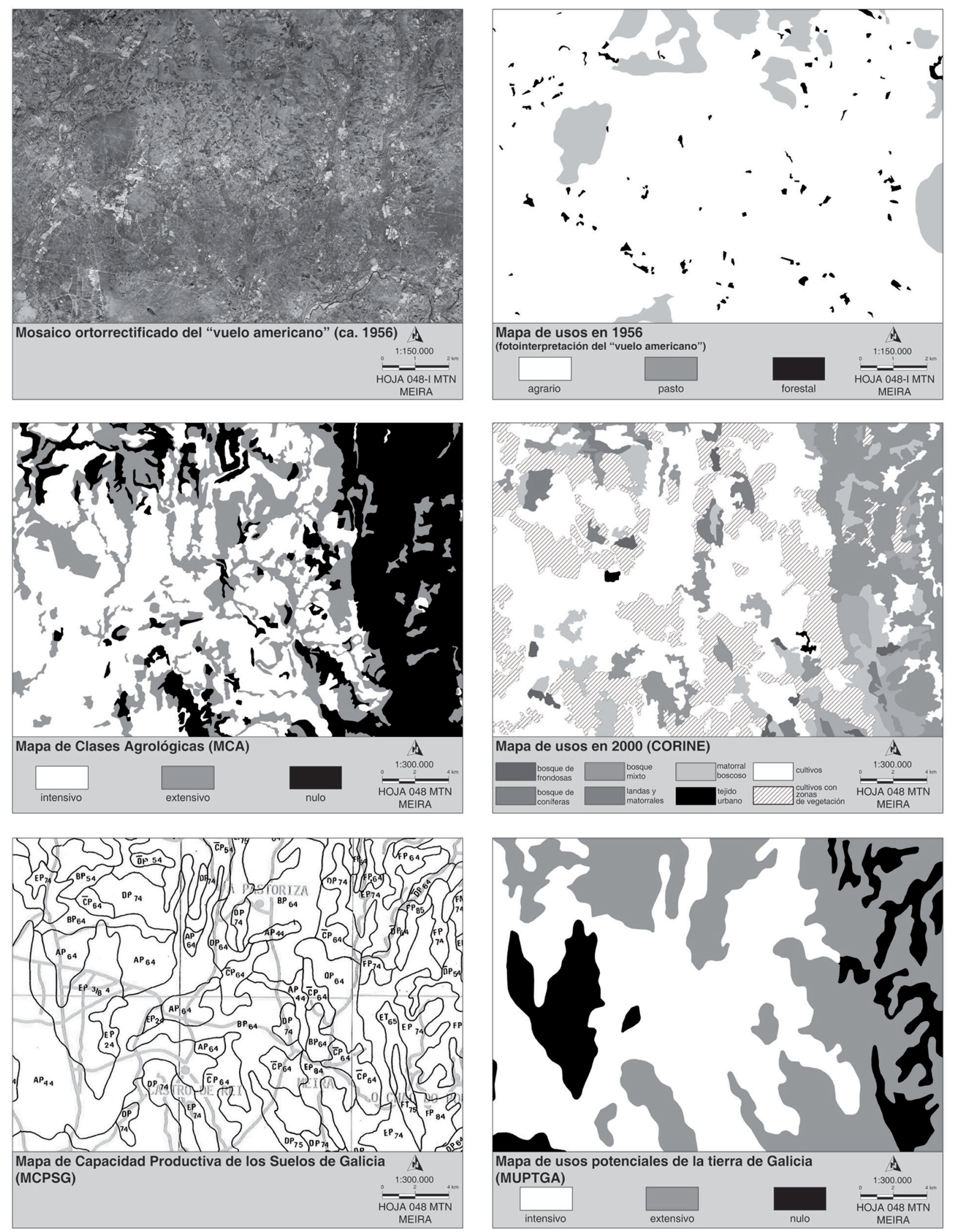

Fig. 3. Comparativa entre la representación gráfica de distintas formas de análisis de los usos de la tierra en la hoja 048 (Meira) del Mapa Topográfico Nacional (MTN), escala 1:50.000

Trab. prehist., 71, N. ${ }^{\circ}$ 1, enero-junio 2014, pp. 23-41, ISSN: 0082-5638 doi: $10.3989 /$ tp.2014.12122 


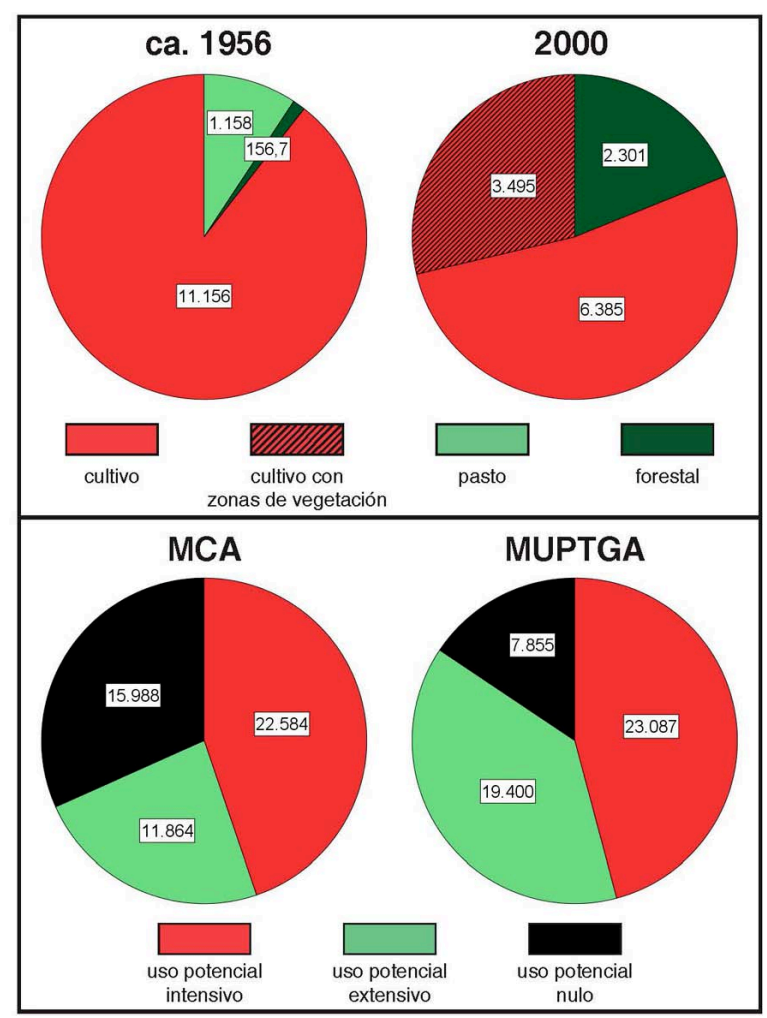

Fig. 4. Comparativa de los usos de la tierra entre los años 1956 y 2000, y de los usos potenciales entre el Mapa de Usos Potenciales de la Tierra de Galicia y el Mapa de Clases Agrológicas para la hoja 048-I Mapa Topográfico Nacional, escala 1:25.000.

Al comparar el MCA con la reclasificación del MCPSG en usos potenciales se observan claramente las diferencias. El Mapa de usos potenciales de la tierra de Galicia (MUPTGA) ofrece una mayor generalización: su escala más amplia contrasta con la mayor definición de las otras dos fuentes. Como contrapartida, su diferenciación mucho más matizada de los tipos de tierra permite valorarlos desde un punto de vista diacrónico.

Los criterios económicos presentistas para evaluar la tierra impiden comprender el empleo de lógicas económicas alternas. El análisis de los sistemas productivos de la agricultura de la antigüedad requiere otra óptica que la que busca el desarrollo de una agricultura intensiva con fines de mercado. El MUPTGA presenta una herramienta alternativa orientada a la visión integral del poblamiento y de su relación con los recursos. $\mathrm{Su}$ aplicación a las zonas que deberían ser consideradas como de potencial nulo es muy expresiva. Estas tierras muy pesadas, formadas por sue- los cuya elevada acumulación de agua supone un inconveniente para el desarrollo de la agricultura, aparecen como tierras de cultivo en el MCA y el $C L C$. Sin embargo desde la perspectiva de la agricultura antigua son poco aptas. Al contrario los suelos más ligeros y drenados, poco productivos para la lógica moderna según el MCA y el $C L C$, se consideran en el MUPTGA especialmente aptos para una economía preindustrial.

En resumen, el MCA y el CLC esconden la multitud de usos posibles del suelo por distintas formas económicas. En la zona tomada como ejemplo, el MCA clasifica como improductiva o no laborable una gran extensión de tierra localizada en el cuarto oriental del mapa. Sin embargo allí el MUPTGA recoge importantes áreas con un predominio de pendientes inferiores al $25 \%$ y sin restricciones edafológicas destacables en donde sí es posible una agricultura extensiva. Cuantitativamente la superficie total de tierra de uso potencial extensivo es de $11.863,5$ ha en el MCA, mientras que en el MUPTGA asciende a: 19.400 ha (Fig. 4). Esta discrepancia tiene su correlato en la evaluación de la tierra de potencial nulo: sólo $7.855,13$ ha en el MUPTGA frente a las 15.988 ha del MCA. Es evidente el sesgo presentista de los mapas de clases.

\section{PROCEDIMIENTO PARA LA DIGITALIZACIÓN DEL MAPA}

Una vez determinados los criterios para la conversión del MCPSG en función de sus usos potenciales, procedí a la digitalización y georreferenciación del mapa resultante. La conversión del MUPTGA a un formato digital compatible con el análisis territorial mediante SIG hace posible su aplicación en diferentes estudios territoriales, tanto a una escala local o comarcal, como con un carácter extensivo a nivel de todo el territorio gallego.

Escaneé las 19 hojas que componen el MCPSG y las ensamblé dando forma a un mosaico, empleando el software Adobe Photoshop CS4®. Según los criterios establecidos, coloreé cada una de las unidades fisiográficas conforme a un código de tres colores correspondiente con los tres usos potenciales del suelo. El tratamiento mediante el software ArcGis 9.3® permite la vectorización automática de una imagen ráster. Para la vectorización creé una imagen del mapa de usos 
potenciales de Galicia compuesta por tres únicos valores de píxel, cada uno identificado con un uso potencial. Previamente filtré la imagen original con Adobe Photoshop CS4® hasta eliminar los bordes que en la cartografía delimitan las unidades fisiográficas y establecí una corrección selectiva de elementos como carreteras, núcleos urbanos, toponimia, etc. que suponen un ruido añadido. Como paso previo a la vectorización final de la imagen, mediante una reclasificación con ArcGis 9.3® fijé los tres valores de pixel.

La georreferenciación del documento digitalizado presenta varios inconvenientes derivados de la escala de partida del MCPSG: 1:200.000 elaborada a partir de una base original a 1:50.000. Como la escala de los análisis de territorio desde la arqueología del paisaje suele ser mucho menor, se requiere una ubicación precisa de las unidades fisiográficas identificadas en el MCPSG para evitar generar una discordancia entre ambos niveles. Para maximizar la precisión cartográfica del MCPSG, llevé a cabo la georreferenciación sobre el MTN escala 1:25.000 mediante todos los elementos susceptibles de ser ubicados. Empleando el software ArcGis $9.3 \AA$ me basé el borde del mapa como elemento clave, complementado con la localización de ríos, núcleos urbanos, y embalses.

Tomé 310 puntos de control para la georreferenciación con un sistema de transformación de $2 .^{\circ}$ orden. Ello generó un error cuadrático medio ligeramente superior a los $300 \mathrm{~m}$. Esta desviación, notablemente elevada, se explica por la discrepancia entre la precisión del trazado cartográfico del mapa de partida y la de los elementos tomados como referencia. Por ejemplo, existe una insalvable discordancia entre la representación del borde de Galicia en la cartografía 1:25.000 sobre la que he llevado a cabo la georreferenciación y en el MCPSG, donde posee una ancho de unos $150 \mathrm{~m}$. He intentado reducir la imprecisión derivada de la conversión de la escala original supervisando el control de calidad por la pendiente. Sobre el Mapa Digital de Elevaciones (MDE) de $25 \mathrm{~m}$ reclasifiqué el mapa de pendientes, según los mismos intervalos empleados en la selección de tipos de suelo. La pendiente es uno de los factores principales en la determinación de las unidades fisiográficas del MCPSG, por lo que cotejarla con el mapa hace posible establecer una delimitación más precisa de los límites establecidos en las unidades fisiográficas en función de las formas del relieve.
La discrepancia entre la base de referencia de escala 1:25.000 y la cartografía de partida de escala 1:200.000 produce una discordancia que se materializa particularmente en los bordes del mapa. La imposibilidad de hacer casar por completo los perfiles de ambas fuentes puede crear puntualmente una reducción o ampliación irreal del suelo accesible. Es cierto que el error por exceso no es un problema real pues los mapas de fricción ya pueden limitar por si mismos la accesibilidad a las partes que rebasan el mapa. Pero, con el fin de evitarlo, ajusté la extensión de la capa de usos del suelo a los límites de Galicia a escala 1:25.0000 y clasifiqué por extrapolación los espacios que quedaban vacíos.

Como último paso, añadí una serie de correcciones sobre el mapa base, controladas por criterios históricos: eliminé elementos como los embalses o los núcleos urbanos, limpié la orla costera de transformaciones modernas e introduje elementos hoy desaparecidos, pero de gran peso, como A Lagoa de Antela, cuyos límites fueron fijados recurriendo a la cartografía histórica correspondiente a la primera edición del MTN a escala 1:50.000 (6).

El resultado final es un archivo.shp compuesto por polígonos, reclasificados en tres tipos de uso potencial de la tierra. Este documento se encuentra accesible en la versión electrónica de la revista http://tp.revistas.csic.es/index.php/tp/ issue/archive (vol. 71, núm. 1, 2014) [doi:10.3989/ tp.2014.12122]. También en formato.kml.

\section{UTILIZACIÓN DEL MAPA DE USOS DE LA TIERRA DESDE UN PUNTO DE VISTA ARQUEOLÓGICO. UNA PERSPECTIVA CRÍTICA}

Las reflexiones de carácter teórico que se derivan de la elaboración del Mapa de usos potenciales de la tierra de Galicia pueden ser válidas para cualquier trabajo de análisis del territorio en términos productivos que maneje fuentes cartográficas de usos de la tierra.

El MUPTGA no representa la realidad, sino una de sus posibles modelizaciones. Las tres clases de uso potencial de la tierra que incluye tie-

(6) Cartografía georreferenciada disponible en el servidor del CNIG: http://centrodedescargas.cnig.es/CentroDescargas/ inicio.do (consulta 27-XII-2013). 
nen un carácter estrictamente orientativo. Reflejan solo un uso ideal que nos sirve como referencia para ponderar la lógica seguida por las estrategias de poblamiento en la elección del emplazamiento. El MUPTGA presenta unas condiciones generales que pueden ser estudiadas desde un punto de vista diacrónico: no cartografía el uso concreto de la tierra en un momento específico. Es decir, los resultados de un análisis de accesibilidad basado en el MUPTGA son aproximados. Los datos sólo muestran la orientación productiva del yacimiento en términos cualitativos.

La representatividad cartográfica del MUPTGA se debe entender igualmente como una modelización. El MCPSG se presenta a una escala 1:200.000 (obtenida a partir de otra 1:50.000) quizás demasiado amplia. Su cierto margen de error queda patente cuando se superpone sobre una base más precisa. Sin embargo, el inconveniente de esta escala puede ser obviado hasta cierto punto, al permitir una visión de conjunto e identificar las estrategias de poblamiento en función de unidades territoriales significativas (Mayoral 2004: 76). Como apuntan sus autores (DíazFierros y Gil Sotre 1984: 33), el MCPSG aporta una escala válida a nivel parroquial, por lo que en conjunto puede ser representativo de la estructuración a nivel comarcal de la capacidad productiva de las tierras gallegas. Otra reducida en exceso podría definir unidades de tierra cuyo tamaño podría llevar a una diversificación poco significativa donde los "árboles no dejaran ver el bosque".

El MUPTGA es una herramienta complementaria a manejar como parte de una metodología particular de análisis territorial. No tiene un valor aislado, ya que ninguna estrategia de poblamiento se define por un único parámetro. Necesariamente tiene que ser combinada con otras variables planteadas en función de las cuestiones que se derivan de un problema histórico (Fernández y Uriarte 2011).

La ponderación del acceso a un tipo de tierra está mediatizada en primer lugar por los criterios que valoran la accesibilidad y las técnicas puestas en juego para la implementación de su cálculo: áreas perimetrales, polígonos de Thiessen, isocronas obtenidas por cálculos de coste establecidos en tiempo, etc. Pero estos resultados por si mismos carecen de valor si no son parte de un programa más amplio de análisis territorial.
La arqueología del paisaje integra múltiples variables seleccionadas en función de las preguntas concretas suscitadas por la investigación. En este sentido, el MUPTGA no está concebido como parte de algo parecido a un "protocolo estándar" aplicable a la investigación arqueológica del territorio. El desarrollo tecnológico de los SIG y la consolidación metodológica de la arqueología del paisaje podrían llevar a replicar procedimientos analíticos aplicados a problemas históricos diferentes en momentos distintos, en vez de generar planteamientos metodológicos específicos derivados del problema histórico mismo. La repetición acrítica de una metodología puede conducir en última instancia a una falsa homogeneización de las interpretaciones históricas o simplemente a su replicación geográfica. El MUPTGA, como cualquier otro recurso técnico, no debe ser un factor condicionante del carácter metodológico de la investigación, de tal modo que pueda acabar formando parte de una hermenéutica determinada por los límites que imponen las herramientas, sin potencial para la interpretación histórica. En la investigación en arqueología del paisaje el conjunto de variables analizado y las herramientas necesarias deben estar indefectiblemente supeditados a los problemas históricos concretos. Volviendo al tema que nos ocupa, el MUPTGA puede tener un papel fundamental en la investigación o ser por el contrario una variable irrelevante.

El MUPTGA no revela modelos agrícolas o económicos. No expresa las formas de acceso a la tierra de un sistema agrícola determinado, ni sus características específicas. El análisis territorial puede mostrar tendencias a ese respecto por parte de las formas de poblamiento, pero el conocimiento de los paisajes de la producción de un sistema socioeconómico tan solo se muestra cuando se interroga al registro en un sentido amplio y se obtiene una visión global (Parcero 2002).

Puede ser significativo aislar un tipo de yacimiento, o un conjunto de yacimientos sincrónicos e identificar una preferencia en sus estrategias locacionales por un determinado tipo de tierra. Sin embargo definir el modelo económico y las formas técnicas con que se desarrolla un sistema agrícola y aportar una interpretación válida del mismo exige combinar distintas fuentes a partir de una lectura integral del registro.

El MUPTGA no revela los usos reales de la tierra, sino la potencialidad de la misma. La re- 
clasificación que incorpora obedece a una idealización que busca ser significativa en el análisis territorial, pero que no tiene por qué corresponderse con los usos reales de un territorio. En realidad, la variabilidad en las formas de uso de la tierra en época antigua es enorme. Por ejemplo, las tierras de potencial intensivo vinculadas a un asentamiento no implican necesariamente que sus habitantes desarrollaran una agricultura compleja. En teoría, tierras de potencial intensivo pudieron cultivarse en un régimen extensivo basado en ciclos largos, y con una sola cosecha al año. Tierras de potencial extensivo o nulo pudieron llegar a ser más productivas por medio de aterrazamientos. Incluso tierras de potencial nulo pudieron ser empleadas por medio de sistemas extensivos. Pienso en el sistema de rozas o estivadas con gran peso en época moderna en gran parte de Galicia (Bouhier 1979) que permitía la explotación de zonas de montaña aparentemente no aptas para la agricultura.

Una arqueología de los espacios agrícolas puede revelar las particularidades del uso de la tierra a nivel microespacial (Ruiz del Árbol 2005). El MUPTGA no participa a esta escala, ya que es solo una herramienta que valorando el potencial aspira a detectar posibles estrategias expresadas en la vinculación a un tipo determinado de tierra.

El MUPTGA no permite acceder a las características de las formas de explotación de un asentamiento singular. Ese estudio exige trabajar a una escala mucho más reducida en donde este mapa pierde toda su significación. A nivel del yacimiento los mapas de usos potenciales de la tierra, sea cual sea su escala, pueden funcionar en un sentido complementario, pero la investigación exige la puesta en práctica de alternativas más específicas como el uso de fotografía aérea, prospecciones sistemáticas, muestreos y sondeos arqueológicos (Ruiz del Árbol 2005; Orejas y Ruiz del Árbol 2008). Las islas Cíes ilustran este extremo. El MUPTGA las caracteriza en su totalidad por un suelo muy pobre, sometido a fuerte erosión y con un máximo déficit hídrico. Sin embargo, hay en la isla un poblado protohistórico (Carballo et al. 1998) y un poblamiento histórico que llega casi hasta la actualidad, lo que denota la existencia de algún tipo de producción agrícola. La causa fundamental de esta discrepancia entre el MUPTGA y los datos históricos es la escala tan amplia de los datos de partida. Una fotointerpretación de detalle muestra zonas propicias para una agricultura de secano junto con otras donde es posible incluso una agricultura intensiva por medio de aterrazamientos. Por otro lado, la práctica de una agricultura de carácter extensivo pudo haberse adecuado perfectamente a suelos ligeros con altos niveles de pedregosidad.

La información del MUPTGA solo tiene sentido en su uso comparado. Los estudios territoriales llevados a cabo desde la arqueología del paisaje no son válidos en su aplicación a un caso concreto aislado, o en la comparación de un número limitado de ellos seleccionados en función de criterios contingentes. La comprensión de los procesos históricos pasa por la evaluación del territorio a escala regional (Orejas 2006).

El valor del MUPTGA es relativo ya que no fija en términos absolutos el acceso a un tipo de tierra, sino que muestra tendencias y estrategias territoriales socialmente significativas, que se ponen en evidencia en el análisis comparado de una muestra geográficamente representativa. El MUPTGA cobra sentido en escalas amplias, en estudios territoriales de escala regional en donde el acceso a un tipo determinado de tierras puede ser significativo de un proceso histórico concreto. Hay cuestiones históricamente relevantes sólo accesibles a partir del trabajo con un volumen de información regionalmente significativo. Entre ellas están las relativas a la existencia de un paisaje organizado en un sentido orgánico o mecánico, de relaciones de dependencia o complementariedad económica, de formas de hábitat especializado, de tendencias aislacionistas o integradoras, etc.

E1 MUPTGA aporta la información más esclarecedora en el análisis diacrónico del territorio combinado con la perspectiva comparada. Los procesos históricos de cambio pueden ir acompañados de transformaciones en las estrategias territoriales y en las formas socioeconómicas. El análisis del acceso a la tierra puede ser una herramienta fundamental para detectarlos y explicarlos.

\section{AGRADECIMIENTOS}

Este trabajo se enmarca en los proyectos de investigación "Paisajes de dominación y resistencia. Procesos de apropiación y control social y territorial en el noroeste hispano (PADORE) 
(HAR2012-33774) y Programa de Investigación para la conservación y revalorización del Patrimonio Cultural" (CONSOLIDER-TCP) (CSD2007-0058, IP Felipe Criado). Agradezco a Almudena Orejas (IP del PADORE, GrI Estructura Social y Territorio-Arqueología del Paisaje, Arqueología y procesos sociales, Instituto de Historia, CCHS-CSIC, Madrid), Antonio Uriarte (Labtel, Instituto de Historia, CCHS-CSIC, Madrid) y María Sebastián (GrI. Prehistoria social y económica, Instituto de Historia, CCHS-CSIC, Madrid) sus valiosos consejos durante su desarro1lo. Las precisiones de los dos evaluadores anónimos han enriquecido el texto final.

\section{BIBLIOGRAFÍA}

Álvarez González, Y. 1993: “Arqueología del paisaje: modelos de ocupación y explotación de los castros del valle de Noceda (León)". Complutum 4: 265278.

Agrafoxo Pérez, X. 1989: O poboamento castrexo na rexión occidental da provincia da Coruña. Grafisant. Santiago de Compostela.

Aira, M. ${ }^{a}$ J.; Saá Otero, P. y Taboada, T. 1989: Estudios paleobotánicos y edafológicos en yacimientos arqueológicos de Galicia. Arqueoloxía/Investigación 4. Xunta de Galicia. A Coruña.

Anón. 1976: A framework for land evaluation. FAO Soils bulletin 32. Food and Agriculture Organization. Roma.

Anón. 1977: Evaluación de recursos agrarios. Mapa de clases agrológicas. Escala 1:50.000. Meira (Lugo). Ministerio de Agricultura. Madrid.

Anón. 1995: Carta de Solos e Carta de Aptidão da Terra de Entre-Douro e Minho. Direção Regional de Agricultura de Entre-Douro e Minho (DRAEDM). Braga.

Attema, P. y de Haas, T. 2005: "Villas and farmsteads in the Pontine region between $300 \mathrm{BC}$ and 300 AD: a landscape archaeological approach". En B. Santillo Frizell y A. Klynne (eds.): Roman villas around the Urbs. Interaction with landscape and environment. Proceedings of a conference at the Swedish Institute in Rome. The Swedish Institute in Rome. Projects and Seminars 2. Roma.

Attema, P. A. J.; Burgers, G. J. y Van Leusen, P. M. 2011: Regional Pathways to Complexity. Settlement and land-use dynamics in early Italy from the Bronze Age to the Republican period. Amsterdam University Press. Amsterdam.

Bouhier, A. 1979: La Galice. Essai geographique d'analyse et d'interpretation d'un vieux complexe agraire. Imprimarie Yonnaise. La-Roche-sur-Yon.
Camino Mayor, J. 1995: Los castros marítimos en Asturias. Real Instituto de Estudios Asturianos. Oviedo.

Carballo Arceo, L. X. 2001: A Cultura Castrexa na Comarca de Deza. Concello de Lalín. Lalín.

Carballo Arceo, L. X.; Luaces Ancas, J.; Toscano Novella, M. ${ }^{a}$ C. 1998: Catálogo do patrimonio arqueolóxico. Arqueoloxía de Vigo e a súa historia. Catálogos do Patrimonio 2. Concello de Vigo. Vigo.

Criado Boado, F. 1992: Arqueología del Paisaje. El área Bocelo-Furelos entre los tiempos paleolíticos $y$ medievales. Arqueoloxía/Investigación 3, Xunta de Galicia. A Coruña.

Díaz-Fierros Viqueira, F. y Gil Sotres, F. 1984: $\mathrm{Ca}$ pacidad productiva de los suelos de Galicia. Mapa 1:200.000. Universidade de Santiago de Compostela. Santiago de Compostela.

Esparza Arroyo, A. y Larrazabal Galarza, J. 2001: “El castro de la Mazada (Zamora): elementos metálicos y contexto peninsular". En V. O. Jorge y J. de Alarcão (eds.): Actas do $3 .{ }^{\circ}$ Congresso de Arqueología Peninsular 5 Proto-história da Península Ibérica (Vila Real, Portugal 1999): 433-475 Porto.

Fábrega Álvarez, P. 2005: "Tiempo para el espacio. Poblamiento y territorio en la Edad del Hierro en la comarca de Ortegal (A Coruña, Galicia)". Complutum 16: 125-148.

Fábrega Álvarez, P.; Parcero Oubiña, C. y Méndez Santiago, P. 2005: "Alén dos castros de O Neixón: análise dixital dunha paisaxe arqueológica". En X. M. Ayán Vila (ed.): Os Castros de O Neixón: recuperación dende a Arqueoloxía dun espacio social e patrimonial. Toxosoutos. Noia: 247-287.

Fábregas Valcarce, R.; Martínez Cortizas, A.; Blanco Chao, R.; Chesworth, W. 2003: "Environmental change and social dynamics in the second-third millennium BC in NW Iberia". Journal of Archaeological Science 30: 859-871.

Fernández Freire, C. y Uriarte González, A. 2011: "Modelización del paisaje mediante SIG para la investigación de sociedades agrarias paleotécnicas". En V. Mayoral Herrera y S. Celestino Pérez (eds.): Tecnologías de información geográfica y análisis arqueológico del territorio. Actas del V simposio internacional de arqueología de Mérida. Anejos de Archivo Español de Arqueología LIX, CSIC. Mérida: 449-458.

Fernández-Posse, M. ${ }^{a}$ D. y Sánchez-Palencia, F. J. 1988: La Corona y el Castro de Corporales II. Truchas (León). Campaña de 1983 y prospecciones en La Valderia y La Cabrera. Excavaciones Arqueológicas en España 153, Ministerio de Cultura. Madrid.

Finke, P.; Harding, J.; Sevink, J.; Sewuster, R.; Stoddart, S. 1994: "Site territories and landuse". En C. Malone y S. Stoddart (eds.): Territory, time and state: the archaeological development of the 
Gubbio Basin. Cambridge University Press. Cambridge: 81-93.

Font Tullot, I. 1988: Historia del clima de España: cambios climáticos y sus causas. Instituto Nacional de Meteorología. Madrid.

Kaal, J.; Carrión Marco, Y.; Asouti, E.; Martín Seijo, M.; Martínez Cortizas, A.; Costa Casáis, M.; Criado Boado, F. 2011: "Long-term deforestation in NW Spain: linking the Holocene fire history to vegetation change and human activities". Quaternary Science Reviews 30: 161-175.

Kamermans, H. 2000: "Land evaluation as predictive modelling: a deductive approach". En G. Lock (ed.): Beyond the Map. Archaeology and Spatial Technologies. NATO Science Series, Series A: Life Sciences 321, IOS Press. Amsterdam: 124-146.

Martínez Cortizas, A.; Costa Casais, M. y López Sáez, J. A. 2009: "Environmental change in NW Iberia between 7000 and 500 cal BC". Quaternary International 200: 77-89.

Martínez Cortizas, A. y Pérez Alberti, A. 1999: Atlas climático de Galicia. Xunta de Galicia. Santiago de Compostela.

Mayoral Herrera, V. 2004: Paisajes agrarios y cambio social en Andalucía oriental entre los períodos ibérico y romano. Anejos de Archivo Español de Arqueología XXXI, CSIC. Madrid.

Orejas, A. 1995: Del "marco geográfico" a la arqueología del paisaje. La aportación de la fotografía aérea. CSIC. Madrid.

Orejas, A. 1996: Estructura social y territorio. El impacto romano en la cuenca noroccidental del Duero. Anejos de Archivo Español de Arqueología XV, CSIC. Madrid.

Orejas, A. 2006: "Arqueología de los paisajes agrarios e historia rural". Arqueología Espacial 26: 7-19.

Orejas Saco del Valle, A. y Ruiz del Árbol Moro, M. 2008: "Territorio y dominio en las villas romanas: el fundus de Veranes". En C. Fernández Ochoa, V. García-Entero y F. Gil Sendino (eds.): Las villae tardorromanas en el occidente del Imperio. Arquitectura y función. IV Coloquio Internacional de Arqueología de en Gijón. Ediciones Trea. Gijón: 168-191.

Orejas Saco del Valle, A. y Sastre Prats, I. 1999: "Fiscalité et organisation du territoire dans le NordOuest de la Péninsule Ibérique: civitates, tribut et ager mensura conprehensus". Dialogues d'Histoire Ancienne 25: 159-188.

Parcero Oubiña, C. 2002: La construcción del paisaje social en la Edad del Hierro del Noroeste Peninsular. Fundación Ortegalia. Ortigueira.

Parcero Oubiña, C.; Fábrega Álvarez, P. 2006: "Diseño metodológico para el análisis locacional de asentamientos a través de un SIG de base "Ráster"". En I. Grau Mira (ed.): La aplicación de los SIG en la Arqueología del Paisaje. Serie Arqueología. Universidad de Alicante: 69-89.

Peña Santos, A. de la 1992: Castro de Torroso (Mos, Pontevedra). Síntesis de las memorias de las campañas de excavaciones 1984-1990. Arqueoloxía/ Memorias 1, Xunta de Galicia. Santiago de Compostela.

Pombo Mosquera, X. A. 1993: "Os castros nas terras de Vilalba". En Galicia da romanidade á xermanización. Problemas históricos e culturais. Actas do encontro científico en homenaxe a Fermín Bouza Brey (1901-1973) (Santiago de Compostela 1992). Museo do Pobo Galego. Noia: 177-189.

Pungín García, A. J. 2009: "Patrones de situación de los asentamientos tipo castro en la comarca de AsFrieiras (Orense)". En Actas do Congresso Transfronteiriço de Arqueologia (Montalegre 2008). Aqvuae Flaviae 41: 237-251.

Ruiz del Árbol Moro, M. 2005: La arqueología de los espacios cultivados. Terrazas y explotación agraria romana en un área de montaña: la sierra de Francia (Salamanca). Anejos de Archivo Español de Arqueología XXXVI, CSIC. Madrid.

Sánchez-Palencia, F. J.; Sastre, I.; Romero, D.; Beltrán, A.; Pecharromán, J. L.; Currás, B. X.; Alonso, F.; Reher, G. 2014: "La minería romana de Pino del Oro y de su entorno inmediato (Zamora)". En F. J. Sánchez-Palencia (ed.): Minería romana en zonas interfronterizas de Castilla y León y Portugal (Asturia y NE de Lusitania). Junta de Castilla y León. Valladolid.

Teira Brión, A. 2010a: "Tierra, metal y semillas. Consideraciones de la agricultura de la Edad del Hierro en Galicia". En A. M. S. Bettencourt, M. I. Caetano Alves y S. Monteiro-Rodrigues (eds.): Alterações Ambientais e Interacção Humana na Fachada Atlântica Occidental. IV Jornadas do Quáternario. $1^{\text {st }}$ International Conference(Coimbra 2011): 133-148. Braga.

Teira Brión, A. 2010b: "Wild fruits, domesticated fruits. Archaeobotanical remains from the roman salwork at O Areal, Vigo (Galicia, Spain)". En C. Delhon y S. Théry-Parisot (eds.): Des hommes et des plantes. Exploitation du milieu et gestion des ressources végétales de la préhistoire à nos jours. XXXe rencontres internationales d'archéologie et d'histoire d'Antibes. Éditions Association pour la promotion et la diffusion des connaissances archéologiques. Antibes: 199-207.

Uriarte González, A.; Vicent García, J. M.; Chapa Brunet, T.; Mayoral Herrera, V.; Pereira Sieso, J.; Cabrera Díez, A. 2008: "Elaboración de mapas de usos potenciales del suelo a partir de datos de teledetección para estudios de arqueología del paisaje: las sociedades protohistóricas en el valle del Guadiana Menor (Andalucía oriental)". En S. Rovira Llorens, M. García-Heras, M. Gener Moret e I.

Trab. prehist., 71, N. ${ }^{\circ}$ 1, enero-junio 2014, pp. 23-41, ISSN: 0082-5638

doi: $10.3989 /$ tp. 2014.12122 
Montero Ruiz (eds.): VII Congreso Ibérico de Arqueometría (octubre 2007): 555-567. Madrid.

Vázquez Mato, M. 2010: “Estrategias de asentamiento como indicadores de cronología relativa para la Edad de Hierro en el noroeste ibérico". Herakleion 3: 67-103.

Van Joolen, E. 2002: "Potential Land Evaluation in Archaeology". En P. Attema, G. J. Burgers, E. Van Joolen, M. Van Joolen, M. Leusen y B. Mater (eds.): New Developments in Italian Landscape Archaeology. British Archaeological Reports, International Series 1091, Archaeopress. Oxford: 185-188.

Van Joolen, E. 2003: Archaeological land evaluation: a reconstruction of the suitability of ancient lands- capes for various land uses in Italy focused on the first millennium $B C$. University of Groningen.

Verhagen, P. 2002: "Some considerations on the use of archaeological land evaluation". En P. Attema, G. J. Burgers, E. Van Joolen, M. Van Joolen, M. Leusen y B. Mater (eds.): New Developments in Italian Landscape Archaeology. British Archaeological Reports, International Series 1091, Archaeopress. Oxford: 200-204.

Xusto Rodríguez, M. 1993: Territorialidade castrexa e galaico romana na Galicia Suroriental: a terra de Viana do Bolo. Anexos do Boletín Auriense 18, Museo Arqueolóxico Provincial de Ourense. Ourense. 